\title{
ESTADO DO CONHECIMENTO DA EAD NO NORTE E NORDESTE COM BASE NOS TRABALHOS DO EPENN
}

\author{
STATE OF KNOWLEDGE OF EAD IN NORTH AND \\ NORTHEAST BASED ON THE WORKS OF EPENN
}

\section{ESTADO DEL CONOCIMIENTO DE LA EAD EN EL NORTE Y NORDESTE CON BASE EN LOS TRABAJOS DEL EPENN}

\author{
Marluce Torquato Lima Gonçalves \\ Professora Doutora da Universidade Estadual do Ceará (UECE) \\ Tauá - Ceará, Brasil. \\ marluce.torquato@uece.br \\ João Batista Carvalho Nunes \\ Professor Doutor da Universidade Estadual do Ceará (UECE) \\ Fortaleza - Ceará, Brasil. \\ joao.nunes@uece.br \\ Amanda Nobre de Aguiar \\ Mestre em Educação pela Universidade Estadual do Ceará (UECE) \\ Fortaleza - Ceará, Brasil \\ amandanobre01@gmail.com
}

\section{Resumo}

O estado do conhecimento compreende o levantamento e a análise da produção acadêmica em determinada área, limitada a um tipo de publicação, de modo a oferecer um panorama dos principais aspectos investigados em períodos e lugares distintos. Este estudo tem como objetivo analisar a produção científica do Norte e Nordeste na área da Educação a Distância (EaD), com foco nas publicações do Encontro de Pesquisa Educacional do Norte e Nordeste (EPENN). Adotou-se o paradigma construtivista e, como método, a pesquisa documental. Foram analisados 66 de um total de 4.018 trabalhos publicados como "Comunicação Oral" nas edições do EPENN de 2009 a 2014. Os resultados revelaram, entre outros aspectos, o número ainda reduzido de trabalhos sobre EaD nesse evento ao se comparar com a expansão da área no Brasil, assim como a necessidade de maior atenção dos pesquisadores quanto à qualidade dos trabalhos científicos apresentados.

Palavras-chave: Pesquisa Educacional. Educação a Distância. EPENN.

\begin{abstract}
The state of knowledge comprises the survey and analysis of academic production in a given area, limited to one type of publication, to offer an overview of the main aspects investigated in different period and places. This study aims to analyze the scientific production in the North and Northeast on Distance Education (DE), with a focus on publications of the Educational Research Meeting of the North and Northeast (EPENN). The constructivist paradigm was adopted and, as a method, the documentary research. 66 of 4,018 works published as "Oral Communication" in EPENN editions 2009-2014 were analyzed. The results revealed, among other aspect, the still small number of studies on distance education in this event when compared with the expansion of the area in Brazil, as well as the need for greater attention from researchers about the quality of scientific works presented.
\end{abstract}

Keywords: Educational Research. Distance Education. EPENN.

\section{Resumen}

El estado del conocimiento comprende el estudio y análisis de la producción académica en un área determinada, limitado a un tipo de publicación, de modo a ofrecer una visión general de los principales

Artigo recebido em agosto 2018. Aprovado em fevereiro de 2019. 
aspectos investigados en tiempos y lugares diferentes. Este estudio tiene como objetivo analizar la producción científica en el Norte y Nordeste en el área de Educación a Distancia (EAD), con un enfoque en las publicaciones del Encuentro de Investigación Educativa del Norte y Nordeste (EPENN). Se adoptó el paradigma constructivista y, como método, la investigación documental. Se analizaron 66 de un total de 4.018 obras publicadas como "Comunicación Oral" en las ediciones del EPENN de 2009 hasta 2014. Los resultados mostraron, entre otras cosas, el aún pequeño número de estudios sobre la educación a distancia en ese evento en comparación con la expansión del área en Brasil, así como la necesidad de una mayor atención por parte de los investigadores acerca de la calidad de los trabajos científicos presentados.

Palabras clave: Investigación Educativa. Educación a Distancia. EPENN.

\section{INTRODUÇÃO}

A educação a distância (EaD) é tema instigante em face da expansão ocorrida nos últimos anos, demandando, para os pesquisadores, o desafio de produzir saber, estabelecer caminhos e fornecer serviços e insumos, que atendam à necessidade de aperfeiçoamento dessa modalidade de ensino e da formação profissional e acadêmica para a prática e a pesquisa nesse campo. Analisar a produção científica das regiões Norte e Nordeste nessa área é fundamental, em um tempo de intensas mudanças consorciadas com avanços da ciência e da tecnologia. É tarefa relevante, em razão do crescimento exponencial do número de instituições e cursos que adotam essa modalidade de ensino.

Nos anos 1990, houve vertiginoso crescimento da EaD no Brasil, fomentada pelo avanço das tecnologias de informação e comunicação e pelas políticas de educação nessa área (KIPNIS, 2009). No período de 2002 a 2012, deve-se destacar a maior evolução dos cursos de graduação a distância em relação aos presenciais. Enquanto em 2002, era inexpressiva a participação da modalidade de educação a distância, representando aproximadamente 1,2\% do total, em 2012 ela respondia por 15,8\% do número de matrículas na graduação (INSTITUTO NACIONAL DE ESTUDOS E PESQUISAS EDUCACIONAIS ANÍSIO TEIXEIRA, 2013, 2014).

Como consequência, cada vez mais pessoas se interessam por estudar esta temática, desafiando as instituições públicas a expandir as ofertas, preparar adequadamente os profissionais envolvidos, atentando para a necessidade de realizar projetos pedagógicos capazes de formar pessoas com equidade e qualidade.

Neste estudo, a pergunta norteadora é: quais pesquisas foram desenvolvidas pelos pesquisadores das regiões Norte e Nordeste, na área de Educação a Distância (EaD), que se materializaram em publicações no EPENN? Para respondê-la, por conseguinte, circunscrevemo-nos à análise das publicações realizadas no Encontro de Pesquisa Educacional do Norte e Nordeste (EPENN), tomando como referências as edições dos anos 2009, 2011, 2013 e 2014. O recorte temporal é justificado pela crescente oferta da EaD desde o ano 2006, quando da institucionalização do Sistema Universidade Aberta do Brasil (UAB) e, no nosso entendimento, representa momento fértil para emergirem mais investigações acerca do tema, considerando que, no início do século XXI, surgiram muitas instituições oferecendo cursos por meio da EaD, como "uma nova forma de ensinar e aprender" (ARETIO, 2002, p. 8).

O objetivo explícito da UAB é expandir e interiorizar a oferta de cursos e programas de educação superior por meio de instituições públicas, via educação a distância, oferecendo, prioritariamente, cursos de licenciatura e de formação continuada de professores da educação básica, cursos superiores para formar dirigentes, gestores e trabalhadores em educação básica (BRASIL, 2006).

$\mathrm{Na}$ agenda da educação do Brasil, as inovações tecnológicas e metodológicas voltadas ao trabalho pedagógico são fatores importantes para a melhoria da qualidade educacional (LITTO; FORMIGA, 2009). Nesse sentido, a EaD, que reúne naturalmente os requisitos da tecnologia, pode dar importante contribuição à formação de profissionais e, de maneira especial, à formação de professores, pois congrega meios responsáveis 
pelo desenvolvimento dos sujeitos no ambiente informacional, permitindo a produção e a difusão do conhecimento de maneira exponencial, impulsionando sujeitos e organizações a um processo constante de atualização e aprendizado (RAPOSO, 2012).

No contexto histórico da $\mathrm{EaD}$, há elementos propulsores que contribuem para sua expansão, compreendendo mudanças na docência, que emerge como on-line e independente, desenvolvimento das Tecnologias Digitais de Informação e Comunicação (TDICs), crescimento das demandas de aprendizagem por toda a vida (lifelong learning), entre outros (TRACTENBERG; TRACTENBERG; AZEVEDO JÚNIOR, 2012). Nesse contexto em permanente mudança, é mister compreender como se processa a evolução das produções científicas publicadas nas regiões Norte e Nordeste relacionadas à educação a distância, em especial, as realizadas no EPENN, principal evento da área de Educação dessas regiões.

\section{EDUCAÇÃO A DISTÂNCIA: primeiras aproximações}

Desde seu surgimento, a educação a distância suscita questionamentos quanto a sua definição. Várias tentativas no sentido de conceituar essa modalidade de ensino foram empreendidas por inúmeros autores ao longo dos tempos. Algo que não tem sido tarefa simples, uma vez que essa modalidade evolui juntamente com o ser humano, e incorpora novos mecanismos e estratégias pedagógicas e tecnológicas no decorrer da história de ambos.

É notório que a modalidade incrementou suas possibilidades e seu grau de abrangência e, com efeito, comporta distintos conceitos. Sendo produto fértil de estudo, a EaD é definida por diversos autores, conforme os horizontes de cada período. Aretio (2002) exprime diversas definições de educação a distância propostas por inúmeros autores, com marcas indeléveis correspondentes a cada época.

A educação a distância, na acepção de Moore e Kearsley (2007, p. 2), diz respeito ao ensino e à aprendizagem separados pelo tempo e espaço, mas que envolvem meios tecnológicos e mecanismos organizacionais e administrativos específicos. Consideramna "o aprendizado planejado que ocorre normalmente em um lugar diferente do local do ensino, exigindo técnicas especiais de criação de curso e de instrução, comunicação por meio de várias tecnologias e disposições organizacionais e administrativas especiais."

Sendo assim, a EaD é a expressão usada para denominar a modalidade de ensino que tem como características básicas a separação física entre professor e aluno, bem como o uso de meios técnicos e comunicação em duas vias para que ocorra o ensinoaprendizagem. Moore e Kearsley (2007), com base na proposta de Desmond Keegan, apontam seis elementos característicos para a definição dessa modalidade: separação entre estudante e professor; influência de uma organização educacional, especialmente no planejamento e na elaboração de materiais de aprendizado; uso de meios técnicos - mídia; providências para a comunicação em duas vias ${ }^{1}$; possibilidade de seminários (presenciais) ocasionais; e participação na modalidade mais industrial de educação. Essa última característica, segundo Aretio (2002, p. 38), tem suas origens no pensamento de Otto Peters, ao expressar que a EaD emprega procedimentos industriais, como "a racionalização do processo, a divisão do trabalho e a produção em massa."

Observam-se elementos importantes nas características descritas: a EaD é considerada um sistema tecnológico de comunicação bi e, acrescente-se, multidirecional, que pode ser massivo e substituir a interação pessoal na sala entre professor e aluno e entre alunos; possui alcance social, podendo chegar a um maior número de pessoas; o material didático, elaborado com atenção a determinadas diretrizes pedagógicas, deve substituir a demanda do aluno pelo professor existente no ensino presencial; e precisa favorecer a autonomia do aluno para promover a aprendizagem, coadunando-se com o que defende Aretio (2002).

Em função do avanço tecnológico, pode-se afirmar que essa comunicação atualmente não se restringe apenas a duas vias, mas abrange múltiplas vias (professor-aluno/s, aluno/s-professor, aluno/s-aluno/s etc.). 
Na educação a distância, conforme Aretio (2002, p. 33-34), não se pretende somente garantir que o aluno adquira conhecimentos; é importante capacitá-lo a "[...] aprender a aprender e aprender a fazer porém de forma flexível, forjando sua autonomia em termos de espaço, tempo, estilo, ritmo e método de aprendizagem [...]." O material didático, por exemplo, deve estabelecer um diálogo com o aluno, permitindo-lhe construir a autonomia em seu processo de aprendizagem.

De modo semelhante, o conceito legal de educação a distância presente no Decreto $n^{\circ}$ 5.622/2005, que regulamenta o artigo 80, da Lei $n^{\circ}$ 9.394/1996 (LDB), situa a EaD como uma modalidade educacional em que há separação física entre o aluno e o professor, com a utilização de mídias e tecnologias no processo de mediação. Pelo Decreto, a EaD é a "modalidade na qual a mediação didático-pedagógica ocorre com a utilização de meios e tecnologias de informação e comunicação, com estudantes e professores desenvolvendo atividades educativas em lugares ou tempos diversos" (BRASIL, 2015, art. $1^{\circ}$ ).

Recentemente, a Resolução n 1, de 11 de março de 2016, da Câmara de Educação Superior do Conselho Nacional de Educação, definiu a EaD como:

\begin{abstract}
[...] modalidade educacional na qual a mediação didático-pedagógica, nos processos de ensino e aprendizagem, ocorre com a utilização de meios e tecnologias de informação e comunicação, com pessoal qualificado, políticas de acesso, acompanhamento e avaliação compatíveis, entre outros, de modo que se propicie, ainda, maior articulação e efetiva interação e complementariedade entre a presencialidade e virtualidade 'real', o local e o global, a subjetividade e a participação democrática nos processos de ensino e aprendizagem em rede, envolvendo estudantes e profissionais da educação (professores, tutores e gestores), que desenvolvem atividades educativas em lugares e/ou tempos diversos. (BRASIL, 2016, art. $2^{\circ}$ ).
\end{abstract}

Neste trabalho, adota-se a definição de EaD presente no Decreto $n^{0} 5.622 / 2005$, pois não está restrita à educação superior, como a Resolução CES/CNE n ${ }^{0}$ 1/2016, além de estar em sintonia com o conceito proposto por Moore e Kearsley (2007) em relação à separação espaço-temporal entre estudantes e professores, comunicação mediada por tecnologias, requerendo intencionalidade e sistematicidade.

Resgatando um pouco a história da EaD, observa-se seu surgimento com o uso de correspondências. Segundo Aretio (2002), há autores que remontam às antigas civilizações com o objetivo de encontrar a origem do ensino por correspondência. $O$ autor, inclusive, cita como exemplo as cartas de Platão a Dionísio.

Ainstrução sistematizada na educação a distância, entretanto, tem início com cursos viabilizados pelos correios, comumente denominados de estudos por correspondência ou estudos em casa. Foram muito úteis, no sentido de proporcionar acesso à educação às pessoas residentes em áreas isoladas ou àqueles que não tinham condições de cursar o ensino regular no período apropriado (MOORE; KEARSLEY, 2007). Nunes (2009) nos revela que a primeira notícia sobre EaD de que se tem registro foi o anúncio das aulas por correspondência ministradas por Caleb Philips (20 de março de 1728, na Gazette de Boston, EUA).

Com a evolução das tecnologias, a educação a distância passou a fazer uso de outros meios, tais como o rádio e a televisão. Essas tecnologias possibilitaram o desenvolvimento de novas estratégias na EaD, fortalecendo-a como modalidade de ensino, e tornando possível, cada vez mais, o atendimento de parcelas da população com dificuldades de cursar o ensino regular.

No final do século $X X$, com a expansão das tecnologias digitais de informação e comunicação e da internet, a educação a distância começou a empregar ambientes virtuais de aprendizagem (AVAs) e uma diversidade de recursos que permitissem 0 ensino via web. A EaD assumiu uma interatividade jamais vista, além da rápida emissão 
e distribuição de informações e conteúdos e da utilização da maior gama de recursos da história da humanidade (LITTO; FORMIGA, 2009; MOOORE; KEARSLEY, 2007).

Os avanços nas tecnologias digitais, com destaque para o surgimento e a expansão de computadores, interfaces gráficas, internet, ambientes virtuais de aprendizagem e, mais recentemente, dispositivos móveis, favoreceram a utilização de materiais multimídia interativos, "[...] a criação de páginas para armazenar materiais do curso, o uso de e-mail e fóruns de discussão para apoiar a comunicação entre professores e alunos, bem como a criação de ambientes de aprendizagem online holísticos utilizando AVAs" (CONOLE, 2015, p. 224).

O desenvolvimento tecnológico está em todas as áreas, inclusive a educação, sendo responsável por gerar mudanças nos processos formativos e de comunicação, por meio do uso ferramentas distintas, como AVAs, softwares educativos, sistemas de mensagem instantânea e redes sociais, entre outras.

Esse breve histórico da educação a distância serve para ilustrar o quanto essa modalidade de ensino evoluiu e integrou a vida de várias gerações ao longo da história. Ela já passou por vários estágios de desenvolvimento da humanidade. Possui relação direta com os períodos nos quais estão inseridas e manifestas as evoluções tecnológicas.

Como se pode observar, embora pareça que a EaD é algo novo, surgida com o advento das tecnologias digitais, ela existe há muito tempo e acompanha várias gerações. Aretio (2002), tomando como base a classificação de Garrison (1989), propõe a evolução da EaD ao longo de quatro gerações: aprendizagem por correspondência, aprendizagem por multimeios, aprendizagem telemática e aprendizagem via internet. Ao longo das gerações, não ocorreu a substituição de uma tecnologia pela outra: as novas tecnologias se incorporam e se ajustam às anteriores, criando modelos híbridos.

A evolução da EaD está associada ao desenvolvimento tecnológico, pois é por meio da tecnologia que se dá a comunicação entre professores e alunos. Ao longo de sua história, a EaD avançou muito. $E$, embora haja críticas quanto à $E a D$, não se pode ignorar o fato de que a educação a distância faz parte da evolução do próprio homem.

A sociedade contemporânea vivencia avanços tecnológicos geradores de mudanças nos modos de produzir, usar e disseminar o conhecimento. Muito se discute sobre as potencialidades em torno das tecnologias de informação e comunicação (TICs) e suas aplicações em vários âmbitos, inclusive na educação. Não se pode negar a importância desses meios tecnológicos para a educação, mas, antes de se utilizar a tecnologia em prol do ensino, há que se pensar em algo indispensável para a execução desse ensino: a formação de professores (NUNES, 2012).

No Brasil, a educação a distância é uma realidade em ascensão (LITTO, 2009), podendo adquirir variados formatos e ser utilizada em diversas áreas. Embora haja registros de cursos a distância antes de 1900 no País, apenas em 1996, com a aprovação da Lei de Diretrizes e Bases da Educação Nacional (LDB), há significativo avanço da EaD, tornando-se passível de ser empregada em todos os níveis e modalidades de ensino e na educação continuada (ALVES, 2009). Ademais, o desenvolvimento das tecnologias e comunicações com meios interativos e a popularização da internet contribuíram para o crescimento da EaD (ANDRADE; SANTOS, 2010).

No campo da política pública, fato bem relevante na história da EaD no Brasil foi a criação do Sistema Universidade Aberta do Brasil (UAB), no ano de 2005, e sua institucionalização por meio do Decreto $n^{\circ} 5.800$, de 8 de junho de 2006 . Conforme essa norma, o Sistema UAB é "voltado para o desenvolvimento da modalidade de educação a distância, com a finalidade de expandir e interiorizar a oferta de cursos e programas de educação superior no País" (BRASIL, 2006, art. $1^{\circ}$ ), o que suscitou novos horizontes no campo da EaD em nível superior e na formação de professores no País. Para se ter uma dimensão desse sistema, ele envolve 96 instituições, distribuídas em 720 polos ativos ou provisórios, com a oferta de 727 cursos $^{2}$.

2 Consulta realizada no SisUAB (http://sisuab.capes.gov.br/). 
Existem modalidades cada vez mais ricas e diversificadas de promover a educação a distância, utilizando dispositivos móveis e adaptáveis e infraestrutura adequada ao contexto (CONOLE, 2015). A infraestrutura, entretanto, é um dos maiores desafios da EaD, quando se reporta a regiões pobres, como a Região Nordeste. Gonçalves (2015) evidencia a noção de que, entre os elementos constitutivos da EaD, a infraestrutura se exprime como componente a ser fortalecido, visando ao aperfeiçoamento da formação oferecida por meio da Universidade Aberta do Brasil. Outros estudos enfatizam a ausência de infraestrutura adequada como um elemento que traz dificuldades na oferta de educação a distância, aliada à falta de tempo e de conhecimentos específicos da área (GROSSI; KOBAYASHI, 2013).

A EaD "[...] ocupa um espaço valorizado e de grande importância na política e na economia, tornando-se uma valiosa estratégia de sobrevivência para os profissionais" (GROSSI; KOBAYASHI, 2013, p. 757). A EaD, ademais, expressa um conjunto de oportunidades para apoiar as práticas de ensino e aprendizagem, manifestando características sociais e participativas que fornecem aos aprendizes acesso a materiais didáticos, permitindo a discussão, o compartilhamento e diversas possibilidades de interação e interatividade (CONOLE, 2015).

O acesso à EaD por via dos dispositivos moveis diversifica as oportunidades de aprendizagem em qualquer lugar, sob distintas circunstâncias, e traz subjacente potencial de inovação no ensino e aprendizagem. A educação a distância, nesse contexto de utilização de novas tecnologias, em especial, as de teor social e participativo, potencializa a promoção de abordagens mais abertas para a prática (CONOLE, 2015). Ao imaginar-se, por exemplo, o uso de simuladores em aulas de laboratórios virtuais, evidencia-se uma infinidade de ferramentas para a partilha das discussões. Por sua vez, as redes sociais têm a capacidade de personalizar experiências de aprendizagem de maneira motivadora e integrada, enquanto os jogos podem desenvolver habilidades sociais, entre outras possibilidades.

Os padrões pedagógicos utilizados na EaD devem ser abertos e flexíveis, não se configurando apenas em transposição das metodologias da educação presencial para a educação a distância. Um dos aspectos que devem permear o planejamento de cursos a distância é a adoção de uma teoria de aprendizagem apropriada. Nesse sentido, Siemens e Downes desenvolveram o conectivismo como sistema de aprendizagem para a Era Digital, resultante da experiência da interação do aprendiz com um mundo em constante mudança, no qual informações estão sendo continuamente adquiridas (SIEMENS, 2005).

O conectivismo é guiado pela premissa de que a pessoa deve selecionar as informações por meio da habilidade crítica, percebendo na diversidade de informações oportunidades de conexões. Nessa teoria, um dos princípios fundamentais é a necessidade de manter conexões para facilitar a aprendizagem contínua (SIEMENS, 2006).

Outro conceito bastante difundido na $\mathrm{EaD}$ é o de distância transacional, configurando-se como a distância cognitiva entre professor e aluno em um ambiente de aprendizagem. Não se refere, apenas, à distância geográfica, mas psicológica e educacional.

Para superar este obstáculo, é necessária a existência do diálogo na relação professor e aluno, sendo preciso, também, haver programas de ensino bem estruturados e autonomia, aliando responsabilidade e liberdade para estudar e aprender (MOORE; KEARSLEY, 2007).

A separação espacial na EaD requer comportamentos diferenciados dos sujeitos, investindo em processos pedagógicos e comunicacionais eficazes, capazes de encurtar essa distância. Demanda dos estudantes comportamentos autônomos, independentes, construtivos e flexíveis, aliados a uma estrutura tecnológica compatível, que possibilite uma comunicação fluída e multidirecional. 
Elemento relevante a ser considerado no planejamento de um curso éa permanência do estudante, carecendo de estratégias que permitam o acompanhamento sistemático capaz de identificar aqueles que estão sob o risco de evasão ou de reprovação. Nesse sentido, a analítica da aprendizagem (learning analitycs - LA) pode contribuir, pois é capaz de ensejar modelos preditivos, tomando por base a análise do conjunto de dados produzidos e armazenados no ambiente virtual.

A analítica da aprendizagem é uma área que faz uso de grandes conjuntos de dados, a fim de melhorar a aprendizagem e o ambiente em que ocorre (FERGUSON, 2013). É utilizada também na EaD, visando a possibilitar uma tomada de decisões rápida e fundamentada. Constitui uma área em ascensão, ultimamente, alvo de pesquisas com o objetivo de prever alunos em risco e minimizar os efeitos da evasão na educação a distância (CAMBRUZZI, 2014).

A analítica da aprendizagem pode ser usada por professores e tutores para monitorar o desempenho de seus alunos, fazendo análises por meio de técnicas estatísticas, de mineração de dados e de visualização, de modo a contribuir para a melhoria dos processos educacionais. Docentes podem adaptar seus conteúdos e estratégias pedagógicas, com fundamento nos resultados dos processos de LA. Outras análises sobre dados de estudantes ocorrem retrospectivamente, permitindo que futuros alunos se beneficiem de aprimoramentos nos cursos oferecidos (SCLATER; PEASGOOD; MULLAN, 2016).

Brindley (2015) discute a necessidade de se desenvolver modelos preditivos baseados em pesquisas com analítica da aprendizagem para combater a evasão e a retenção na EaD. As variáveis desses modelos podem ser de natureza demográfica, pedagógica ou institucional.

As abordagens de apoio a estudantes na EaD devem se tornar objetivas, proativas e oportunas, com foco na intervenção precoce quando se tem pesquisas que evidenciam as causas da evasão e da retenção. Brindley (2015), relatando acerca dos resultados das pesquisas dessa área, enfatiza o fato de que problemas de natureza geográfica, de saúde, trabalho, situações familiares, compromissos externos, dentre outros, contribuem, por exemplo, para o abandono do curso.

É necessário que as instituições sejam mais proativas na utilização de métodos e recursos que auxiliem os estudantes desde a escolha do curso que irão fazer, desenvolvam modelos preditivos e tenham atenção às circunstâncias do contexto. A autora ressalta que "[...] muitas instituições fizeram experiências com learner analitycs ${ }^{3}$, mineração de dados em sistemas de gerenciamento de aprendizagem e informação dos alunos para encontrar os preditores mais proeminentes de evasão e retenção" (BRINDLEY, 2015, p. 301). Por meio da análise desses dados, podem ser explorados padrões aptos a direcionar melhor os cursos para que os estudantes obtenham sucesso.

Reportando-se à qualidade na EaD, o conhecido trabalho de Russell (1999), assentado em uma pesquisa que analisa 355 estudos de 1928 a 1998, revelou que não havia diferença estatisticamente significativa entre o ensino presencial e a modalidade de educação a distância, em termos do sucesso dos alunos. Por outro lado, ainda é preciso superar o obstáculo da descrença em relação à EaD por parte de acadêmicos, pelo fato de esta modalidade de ensino ser frequentemente utilizada com objetivos comerciais, em "[...] instituições privadas que visam o (sic) lucro, algumas das quais deixam bastante a desejar em relação à qualidade" (LATCHEM, 2015, p. 320).

O desenvolvimento e as futuras perspectivas em relação à educação a distância podem ser configurados levando-se em consideração a interação e o senso de comunidade, carecendo de um trabalho articulado entre legisladores, planejadores, gestores, equipes de apoio e tutoria, incluindo pesquisadores, a fim de evidenciar a qualidade da EaD e os influxos nos sistemas.

A autora usa a expressão learner analytics (analítica do aprendiz) em vez de learning analytics (analítica da aprendizagem), comumente empregada. 
A EaD pode contribuir para a superação das desigualdades regionais em relação à oferta educacional, ensejando mudanças e criando ambientes de aprendizagem eficazes, que produzam interação e comunicação. A inovação tecnológica, aliada à necessidade de aperfeiçoamento da aprendizagem, direciona para transformações nessa modalidade de ensino, que efetivamente contribuam para consolidar a educação a distância como uma política pública de sucesso que influencie positivamente no desenvolvimento educacional do País. Convém, agora, discutir os caminhos encontrados para a feitura deste artigo.

\section{ASPECTOS METODOLÓGICOS}

As pesquisas denominadas "estados da arte" compreendem "o desafio de mapear e de discutir uma certa produção acadêmica em diferentes campos do conhecimento, tentando responder que aspectos e dimensões vêm sendo destacados e privilegiados em diferentes épocas e lugares" (FERREIRA, 2002, p. 257), com origem em categorias, buscando entender a produção científica. Devem envolver o levantamento de tipos distintos de publicações científicas sobre determinado tema, como artigos de periódicos, livros, trabalhos em eventos, dissertações e teses etc.

Quando essas pesquisas se limitam a um tipo de publicação (exemplo: trabalhos em eventos), Romanowski e Ens (2006) assinalam que são "estados do conhecimento." Estes compreendem, portanto, o levantamento e a análise da produção acadêmica em determinada área, limitada a um tipo de publicação, de modo a oferecer um panorama dos principais aspectos investigados em períodos e lugares distintos. Este artigo adota essa denominação, pois se circunscreve a trabalhos publicados no Encontro de Pesquisa Educacional do Norte e Nordeste (EPENN).

Independentemente da denominação, estudos dessa natureza, segundo Romanowski e Ens (2006, p. 39), acompanham o desenvolvimento, as mudanças e inovações das áreas de conhecimento, podendo se constituir, no caso da educação, como importantes contribuições para se conhecer "os aportes significativos da construção da teoria e prática pedagógica." Podem identificar possibilidades, integração de variadas perspectivas, contradições, lacunas e vieses, ao longo da evolução da Ciência.

Para alcançar tal estado do conhecimento, este ensaio assume o paradigma construtivista, implicando uma ontologia relativista e uma epistemologia subjetivista, de modo que os resultados são criados à medida que a investigação se desenvolve. Sob essa perspectiva, o pesquisador e o objeto da pesquisa assumem ligação interativa, numa relação estreita entre ontologia e epistemologia (GUBA; LINCOLN, 1994).

Adotou-se como método a pesquisa documental, que se utiliza de técnicas para a apreensão, organização, compreensão e análise de documentos dos mais variados tipos (SÁ-SILVA; ALMEIDA; GUINDANI, 2009). É aplicada a documentos, contemporâneos ou não, considerados cientificamente autênticos.

Nesta pesquisa, foram analisados 66 de um total de 4.018 trabalhos publicados como "Comunicação Oral" nas edições do Encontro de Pesquisa Educacional do Norte e Nordeste (EPENN) de 2009, 2011, 2013 e 2014. Esse quantitativo está assim distribuído: 33 trabalhos da edição do EPENN de 2009, 17 de 2011, quatro de 2013 e 12 de 2014.

$\mathrm{Na}$ análise dos textos, realizou-se processo iterativo constituído dos seguintes passos: a) leitura dos textos selecionados; b) identificação/elaboração de categorias, conforme as temáticas nas produções; e c) revisão e agrupamento de categorias, de acordo com o foco do trabalho. Ao final, chegamos à definição de oito categorias que permitem compreender a natureza dos estudos.

O critério utilizado na constituição das categorias foi subjetivo-interpretativo, explicitado na seção seguinte. Consideramos relevante adentrar os aspectos observados nas produções, incluindo conceitos utilizados, objetivos, aspectos metodológicos e 
discussões que norteiam os trabalhos analisados, fazendo reflexões analíticas que podem contribuir para o desenvolvimento de novas pesquisas.

\section{RETRATO DAS PRODUÇÕES ACADÊMICAS DO NORTE E NORDESTE}

A revolução da informação exige profundas mudanças nos processos educacionais e nas teorias pedagógicas (MAIA; MATTAR, 2007). Essas mudanças requerem dos pesquisadores a disposição para desenvolver investigações que proporcionem a evolução do pensamento, do saber e da arte.

O Encontro de Pesquisa Educacional do Norte e Nordeste (EPENN) acontece desde os anos 1970, congregando pesquisadores da área educacional, com frequência bianual. Até a $22^{a}$ edição (2014), era organizado inicialmente pelos Programas de PósGraduação em Educação do Norte e Nordeste e, depois, pelo Fórum de Coordenadores de Programas de Pós-Graduação em Educação do Norte e Nordeste (FORPREd-N/NE), regional do Fórum de Coordenadores de Programas de Pós-Graduação em Educação (FORPREd) ${ }^{4}$.

Dada a necessidade de adequar o calendário dos encontros promovidos pelas cinco regionais do FORPREd com o da Reunião Nacional da Associação Nacional de Pós-Graduação e Pesquisa em Educação (ANPEd), que passou de anual para bianual, o EPENN foi realizado em 2014, a fim de que os encontros de todas as regionais (incluindo o EPENN) acontecessem nos anos pares e a Reunião Nacional da ANPEd ocorresse nos anos ímpares. Cada edição acontece em um estado diferente, sob a coordenação local de uma das universidades do Estado (quadro 1).

Quadro 1 - Edição, cidade, estado e coordenação local do EPENN - 2009-2014.

\begin{tabular}{cclll}
\hline Ano & Edição & \multicolumn{1}{c}{ Cidade } & \multicolumn{2}{c}{ Estado } \\
\hline 2009 & 19 & João Pessoa & Paraíba & Universidade Federal da Paraíba (UFPB) \\
2011 & 20 & Manaus & Amazonas & Universidade Federal do Amazonas (UFAM) \\
2013 & 21 & Recife & Pernambuco & Universidade Federal de Pernambuco (UFPE) \\
2014 & 22 & Natal & Rio Grande do Norte & Universidade Federal do Rio Grande do Norte (UFRN) \\
\hline
\end{tabular}

Fonte: Elaborado pelos autores.

Com a ampliação dos programas de pós-graduação em Educação no Norte e Nordeste, foi decidido que haveria uma regional do FORPREd e um evento para cada uma dessas regiões, de modo a favorecer o fortalecimento da pesquisa e da pós-graduação com o olhar para as especificidades regionais. Desde a $23^{a}$ edição (2016), por conseguinte, o EPENN adotou o nome "Encontro de Pesquisa Educacional do Nordeste (EPEN)", passando a ser organizado pelo Fórum de Coordenadores de Programas de Pós-Graduação em Educação do Nordeste (FORPREd-NE), enquanto o Fórum de Coordenadores de Programas de Pós-Graduação em Educação do Norte (FORPREd-N) criou o evento ANPEd Norte - Reunião Científica Regional Norte da ANPEd.

Nas edições do EPENN de 2009 a 2014, foi contabilizado um total de 4.018 trabalhos publicados como "Comunicação Oral", assim distribuídos: 1.569 em 2009 (39,1\%), 1.358 em 2011 (33,8\%), 386 em 2013 (9,6\%) e 705 em 2014 (17,5\%). Pode se observar que há um decréscimo na quantidade de trabalhos publicados de 2009 até 2013 , voltando a crescer em 2014, sendo o ano de 2009 aquele com a maior quantidade de trabalhos publicados no período e o de 2013 o de menor quantidade (tabela 1).

Tabela 1 - Quantitativo das comunicações orais publicadas no EPENN, sobre EaD e total - 2009-2014

\begin{tabular}{cccccc}
\hline \multirow{2}{*}{ Anos } & \multicolumn{3}{c}{ Trabalhos sobre EaD } & \multicolumn{2}{c}{ Total de Trabalhos } \\
\cline { 2 - 6 } & $f$ & $\%$ na Horizontal & \% na Vertical & $\%$ \\
\hline 2009 & 33 & 2,1 & 50,0 & 1.569 & 39,1 \\
2011 & 17 & 1,3 & 25,7 & 1.358 & 33,8
\end{tabular}

O FORPREd é uma das instâncias da Associação Nacional de Pós-Graduação e Pesquisa em Educação (ANPEd). 


\begin{tabular}{cccccc}
2013 & 4 & 1,0 & 6,1 & 386 & 9,6 \\
2014 & 12 & 1,7 & 18,2 & 705 & 17,5 \\
\hline Total & 66 & - & 100,0 & 4.018 & 100,0 \\
\hline
\end{tabular}

Fonte: Elaborada pelos autores.

Do total de comunicações orais, foram identificados 66 trabalhos que estavam relacionados à educação a distância $(1,6 \%$ do total). Em números absolutos, a quantidade de trabalhos sobre EaD decresce de 2009 a 2013, retomando o crescimento em 2014. Considerando a proporção de trabalhos sobre EaD em relação ao total de cada edição do EPENN do período analisado, observa-se uma sintonia na ordem de grandeza: a menor proporção ocorre em 2013 (1,0\%), edição com a menor aprovação de trabalhos no período considerado (386), e a maior no ano 2009 (2,1\%), edição com a maior aprovação de trabalhos (1.569), conforme tabela 1. Além disso, só a quantidade de trabalhos relacionados à EaD, no EPENN 2009, representa metade daqueles aprovados nas quatro edições investigadas.

Dos 66 trabalhos analisados, observou-se que parte significativa não denotou a estrutura formal esperada em um trabalho científico, de modo que somente $53,0 \%$ (35) continham claramente o objetivo da pesquisa. Em relação aos aspectos metodológicos, $27,3 \%$ (18) definiram a abordagem de pesquisa, 37,9\% (25) explicitaram o método, $21,2 \%$ (14) relataram as técnicas de coleta de dados e apenas 13,6\% (9) apresentaram claramente as técnicas de análise de dados utilizadas. Os estudiosos afirmam que, para pesquisar, precisamos de métodos e técnicas que nos levem criteriosamente a resolver problemas: "[...] é pertinente que a pesquisa científica esteja alicerçada pelo método, o que significa elucidar a capacidade de observar, selecionar e organizar cientificamente os caminhos que devem ser percorridos para que a investigação se concretize" (GAIO; CARVALHO; SIMÕES, 2008, p. 148).

Entre os que explicitaram o método (25), 48,0\% (12) realizaram estudo de caso. Os demais utilizaram: pesquisa bibliográfica, exploratória, empírica, de campo, pesquisa-ação, análise documental, mapeamento em base de dados e ex post facto. A abordagem foi qualitativa entre todos que explicitaram esse aspecto, com exceção de três trabalhos definidos como "pesquisa com métodos mistos".5. Está configurada a abordagem qualitativa como a mais utilizada pelos pesquisadores em Educação nos trabalhos apresentados no EPENN para o período analisado.

Foram encontrados $37,9 \%$ (25) dos trabalhos com discussões teóricas bem fundamentadas, sem apresentar, todavia, o objetivo da investigação ou fazer qualquer referência aos aspectos metodológicos. Há também aqueles que se constituem relatos de experiências. Desta análise, depreende-se a necessidade de as instituições de ensino superior investirem no fortalecimento da formação para a pesquisa científica, incluindo suas características e aplicabilidade, visando a fomentar cientificidade nas investigações desenvolvidas, para o que já alertavam Shavelson e Towne (2002).

Das produções encontradas, 45,5\% (30) situaram a educação a distância no contexto de expansão e crescente desenvolvimento das inovações tecnológicas e pedagógicas, reafirmando-a como política educacional, regulamentada pela legislação vigente. Os trabalhos são unânimes em considerar a EaD como modalidade de ensino nos termos do Decreto $n^{\circ} 5.622 / 2005$.

Os conceitos de EaD nos trabalhos analisados situam-se em torno da legislação, coadunando com autores diversos, a exemplo de Moran (2007), que concebe a educação a distância como processo de ensino e aprendizagem, mediado por tecnologias, no qual professores e alunos estão separados espacial e/ou temporariamente.

Entende-se a EaD como modalidade que possui características específicas, como: interatividade, aprendizagem a distância, flexibilidade de espaço/tempo, redes colaborativas, maior autonomia dos alunos, integração de mídias e linguagens, dentre 5 A pesquisa com métodos mistos combina abordagens qualitativa e quantitativa ao longo do processo de pesquisa (CRESWELL; CLARK, 2013). 
outros fatores que influenciam as interações virtuais. Esse pensamento é referendado por diversos autores, dentre eles Tedesco, Martins e Santos (2010).

Os trabalhos destacam a EaD como um fértil campo que utiliza as tecnologias, e estas se caracterizam por serem evolutivas, ou seja, estão em permanente transformação. Destacam-se também por terem "uma base imaterial, ou seja, não são tecnologias materializadas em máquinas e equipamentos. Seu principal espaço de ação é virtual e sua principal matéria-prima é a informação" (KENSKI, 2007, p. 25).

Os assuntos analisados nos textos denotam uma diversidade própria da área da EaD, revelando que essa modalidade faz uso de tecnologias diversas. O agrupamento dessas produções em categorias de assuntos foi tarefa que exigiu reflexão e leitura minuciosa dos trabalhos, a fim de evitar distorções e equívocos. O resultado obtido está sintetizado na tabela 2.

Tabela 2 - Categorias de assuntos das comunicações orais publicadas no EPENN - 2009-2014

\begin{tabular}{lcc}
\hline \multicolumn{1}{c}{ Categorias } & Trabalhos & Percentual \\
\hline Análise de curso em AVA & 21 & 31,8 \\
Formação de profissionais & 17 & 25,8 \\
Tutoria & 9 & 13,6 \\
Tecnologias e inclusão digital & 7 & 10,6 \\
Aprendizagem na EaD & 4 & 6,1 \\
Análise de material didático (EaD) & 3 & 4,5 \\
Educação corporativa & 2 & 3,0 \\
Outros & 3 & 4,5 \\
\hline Total & 66 & 100,0 \\
\hline
\end{tabular}

Fonte: Elaborada pelos autores.

Vale salientar que o assunto mais abordado nos trabalhos investigados era a Análise de Curso em Ambiente Virtual de Aprendizagem (AVA). Os autores versaram nos textos sobre a contribuição do ambiente virtual de aprendizagem para a EaD, as múltiplas possibilidades de uso de um AVA e suas especificidades. As discussões incluem análise dos projetos pedagógicos, avaliação de cursos e sistemas, dentre outros aspectos que envolvem o aluno on-line. O Moodle (Modular Object-Oriented Dynamic Learning Environment), um software livre, aparece como o AVA utilizado em 15 trabalhos. Os demais não especificam o ambiente virtual de aprendizagem empregado, à exceção de um trabalho que cita a plataforma denominada Solar, utilizada pela Universidade Federal do Ceará.

Outro aspecto relevante incluso nessa categoria foi o tempo na EaD. Os autores buscaram identificar as dificuldades dos cursistas na realização das atividades dos cursos, verificando acessos e conteúdos propostos, assim como avaliando as atividades que não foram respondidas no tempo sugerido. Destacam que o cumprimento das tarefas dentro de um curso realizado a distância envolve a disciplina individual, a autonomia necessária na educação a distância e a reflexão das instituições para um planejamento direcionado ao sucesso dos alunos, atendendo suas necessidades, principalmente quando compreende a conciliação entre trabalho e estudo.

Os cursos analisados nos estudos foram nas áreas de: ensino médio - Proinfantil e Proformação; graduação - Administração, Computação, Hotelaria, Letras/Português e Pedagogia; especialização - Gestão Escolar, Educação a Distância e Programa Mídias na Educação; Programa de Capacitação a Distância para Gestores Escolares (Progestão). Observou-se que os cursos de graduação e especialização avaliados são ofertados por meio da UAB. Os cursos de ensino médio utilizam material impresso, momentos presenciais, a distância e acompanhamento da prática pedagógica do cursista em formação.

A Formação de Profissionais é uma categoria que compreende a formação de professores e gestores, incluindo as discussões sobre o papel dos professores formadores no exercício da docência na educação a distância, a importância da 
formação nessa modalidade de ensino, com possibilidade de atender maior universo de pessoas. Conforme anunciado no início deste artigo, com a criação da UAB, houve maior expansão da EaD no Brasil. Os trabalhos do EPENN retrataram essa oferta, analisando a formação oferecida, as influências e contribuições para a prática educacional. Para Mota (2009, p. 297), a missão específica do sistema UAB "diz respeito ao compromisso de formação de professores e consequente melhoria da educação básica." Com efeito, essa expansão proporcionou a abertura para a EaD conquistar credibilidade, com potencial alcance social.

A EaD pressupõe o apoio de uma Tutoria, composta de profissionais que atuam colaborativamente. As produções relacionadas a essa categoria situam o tutor e seus papéis na constituição de uma práxis baseada na experiência profissional. Destacam a necessidade de investimento sólido na formação dos tutores, de modo a preparálos para atuar na educação on-line, na utilização de mapas conceituais, constituindo um ambiente telemático de aprendizagem colaborativa. Enfatizam o papel da tutoria voltado para a orientação acadêmica, acompanhamento pedagógico e aprendizagem dos alunos. Efetivamente, a mediação emerge como um processo educacional, humano e social que acontece na e pela interação (MAIA; MATTAR, 2007). Corroboramos essas ideias, visto que o tutor identifica dificuldades e medeia o ensino-aprendizagem, seja presencial ou por meio de variados recursos tecnológicos. Segundo os Referenciais de Qualidade para Educação Superior a Distância, o tutor deve ser compreendido como partícipe ativo da prática pedagógica e "suas atividades desenvolvidas a distância e/ ou presencialmente devem contribuir para o desenvolvimento dos processos de ensino e de aprendizagem e para o acompanhamento e avaliação do projeto pedagógico" (BRASIL, 2007, p. 21).

Tecnologias e Inclusão Digital foi a quarta categoria mais abordada. Os trabalhos incursionaram pelas implicações da EaD no ensino, sobre a produção de fontes digitais no ciberespaço e a expansão da EaD na era dinâmica da internet. Também examinaram os dispositivos tecnológicos como estratégias discursivas, fazendo uma reflexão crítica sobre o uso da tecnologia no discurso oficial. Dada a importância dessa categoria no mundo da sociedade em rede, discutem-se características como flexibilidade e abertura, como desafios postos à inserção de mais pessoas no universo das tecnologias.

Na categoria Aprendizagem na EaD, há trabalhos nos quais os autores discutem aspectos voltados para as concepções de aprendizagem, utilizando a tecnologia. Refletem sobre o conceito de aprendizagem colaborativa, como novo modo de ensinar e aprender nesta realidade de inovações e mudanças do século XXI. Interatividade e aprendizagem colaborativa são conceitos que precisam estar constantemente sendo revisitados em razão dos avanços da tecnologia, quando são criadas outras modalidades de colaboração e interação (MATTAR, 2009). É imprescindível, portanto, a apropriação desses conceitos pelos estudiosos da EaD.

A categoria Análise de Material Didático está em dois trabalhos, que versavam sobre estratégias linguístico-discursivas, refletindo sobre os textos escritos e utilizados na educação a distância, de modo a adquirirem caráter interacional, dialogal e envolvente, condições essenciais para a ocorrência de mediação pedagógica. O terceiro analisa a adoção do ciclo $\mathrm{PDCA}^{6}$ nos processos de elaboração de conteúdos didáticos para a EaD, visando à busca contínua da melhoria da qualidade. É importante que os materiais didáticos voltados para a educação a distância sejam elaborados por profissionais experientes nesta modalidade de ensino, distribuídos por meio de tecnologias interativas, objetivando favorecer a autonomia do aluno e os aspectos intersubjetivos (MAIA; MATTAR, 2007).

Com o avanço tecnológico e a utilização da EaD em todas as esferas da vida social, a Educação Corporativa se abre para novo modelo de formação e desenvolvimento pautado no ideário de qualidade e produtividade (MARTINS, 2009). Dois trabalhos,

Ciclo de quatro passos utilizado no controle de qualidade de processos e produtos. Significa Plan-Do-Check-Act (Planejar-Executar-VerificarAgir) (AGGARWAL; LYNN, 2012). 
entre os analisados, trataram dessa temática, retratando a experiência da criação da Escola de Gestão Pública do Estado do Ceará e da análise de uma experiência de curso ofertado para militares. Com efeito, essa área mostra potencialidade para crescer, constituindo-se campo fértil para a realização de pesquisas.

$\mathrm{Na}$ categoria Outros, inserimos temáticas específicas que apareceram apenas em três trabalhos. São elas: analítica da aprendizagem (learning analytics) na EaD, evasão e contribuições sobre os fundamentos da educação para o debate da EaD, à luz do tecnicismo. No trabalho sobre analítica da aprendizagem na EaD, Nunes, Nobre e Sampaio (2013) estabelecem um retrato da produção acadêmica brasileira acerca desse tema e o situam como campo fértil para realização de pesquisas no Brasil, visto que não foram encontradas produções sobre o assunto em teses e dissertações, periódicos nacionais qualificados como A1 e A2 na área de Educação e trabalhos completos das reuniões anuais da ANPEd ou edições do Congresso Internacional ABED de Educação a Distância (CIAED), para o período analisado.

No texto Evasão nos Cursos de Educação a Distância da UAB/UFAL, Pinto (2009) buscou identificar os fatores que influenciam o abandono e estabelecer uma crítica aos modelos de formação engessados e padronizados. O autor desse trabalho aponta diversas causas para a evasão, como a insatisfação com o tutor, dificuldade de acesso à internet, complexidade das atividades, dificuldade de assimilação da cultura inerente à EaD, falha na elaboração do curso, expectativas erradas por parte dos alunos, tecnologia inadequada ou falta de habilidade para usar a tecnologia corretamente, além da falta de tempo como maior dos problemas, seguido da falta de dinheiro. No trabalho O Tecnicismo Revisitado: contribuições dos fundamentos da educação para o debate da educação s distância (EAD), Sabbatini (2014) faz um levantamento em bases de dados nacionais e internacionais acerca dos fundamentos sociofilosóficos da EaD, objetivando aprofundar a base teórica desta modalidade de ensino. Como resultado, aponta que a precarização do trabalho docente, direciona "para um cenário potencialmente pessimista em relação à utilização da EaD para a superação dos problemas educacionais brasileiros" (SABBATINI, 2014, p.15).

Nas quatro edições do EPENN analisadas, o tema da educação a distância foi abordado em publicações distribuídas em sete grupos de trabalho (tabela 3), correspondendo a $29,2 \%$ dos 24 grupos considerados no evento ${ }^{7}$. Segundo a ANPEd, os grupos de trabalho (GTs) são "instâncias de aglutinação e de socialização do conhecimento produzido pelos pesquisadores da área de educação"8. O GT 16 Educação e Comunicação possui a maior quantidade de publicações relacionadas à EaD, compreendendo $72,7 \%$ (48) dos trabalhos. Esse resultado ratifica o foco do GT, cujas pesquisas envolvem os processos de comunicação e o uso de mídias e tecnologias distintas na educação. Na sequência, o GT 08 - Formação de Professores - aparece em segundo lugar, respondendo por $15,2 \%$ (10) dos trabalhos analisados; enquanto o GT 11 - Política da Educação Superior - aglutina 6,1\% (4) dos trabalhos. Nos demais GTs citados na tabela 3, somente foi encontrado um trabalho em cada.

Tabela 3 - Comunicação oral por grupos de trabalho no EPENN - 2009-2014

\begin{tabular}{ccc}
\hline Grupos de Trabalho & Quantidade & Percentual \\
\hline 05 & 1 & 1,5 \\
08 & 10 & 15,2 \\
11 & 4 & 6,1 \\
14 & 1 & 1,5 \\
15 & 1 & 1,5 \\
16 & 48 & 72,7 \\
19 & 1 & 1,5 \\
\hline Total & 66 & 100,0
\end{tabular}

Embora somente existam 23 GTs na ANPEd (2 a 24), foi incluído o GT 25 - Educação no Campo na 19a edição do EPENN (2009).
ANPED ([201-]).

Cad. Pesq., São Luís, v. 26, n. 1, p. 107-124, jan./mar., 2019. 
Analisando a origem dos autores dos 66 trabalhos (tabela 4), emergem 28 instituições. Há escritos com autores pertencentes a instituições diferentes. Observamse que $96,4 \%$ (27) são de educação superior, sendo 14 instituições de educação superior (IES) federais, 10 IES estaduais e três de natureza privada. Observa-se que a UFAL é a instituição de educação superior com maior número de publicações na área da EaD, representando 18,2\% (12) do total de trabalhos analisados. Em seguida, UNEB e UFC são as que possuem maior quantidade de trabalhos, respondendo cada uma por $16,7 \%$ (11) e 10,6\% (7), respectivamente, da produção analisada. Esses resultados revelam que há muito espaço para crescimento de pesquisas nessa área nas demais instituições.

No item "Outras" da tabela 4, foram reunidas as instituições de autores que publicaram apenas um trabalho. São elas: Universidade Estadual do Maranhão, Universidade Estadual do Amazonas, Universidade Estadual de Alagoas, Instituto Federal de Alagoas, Escola de Gestão Pública do Estado do Ceará, Universidade Estadual de São Paulo, Universidade Federal do Amazonas, Universidade Federal de Rondônia, Universidade Estadual do Pará, Universidade da Amazônia, Universidade Federal Rural do Semi-Árido, Universidade Federal de Campina Grande, Universidade do Norte do Paraná e Universidade Estadual do Sudoeste da Bahia.

Considerando o nível ou etapa da educação objeto de estudo dos trabalhos analisados, verificou-se que $83,3 \%$ (55) foram dirigidos ao ensino superior, no âmbito da graduação, enquanto 7,6\% (5) se detiveram no nível de especialização e 3,0\% (2) focaram na extensão. Menor número de trabalhos olhou para a educação básica: $4,5 \%$ (3) adotaram como objeto o ensino médio; enquanto 1,5\% (1) o ensino fundamental.

Tabela 4 - Instituições dos autores de comunicação oral sobre EaD no EPENN - 2009-2014

\begin{tabular}{lcc}
\multicolumn{1}{c}{ Instituições } & Trabalhos & Percentual $^{*}$ \\
\hline Universidade Federal de Alagoas (UFAL) & 12 & 18,2 \\
Universidade Estadual da Bahia (UNEB) & 11 & 16,7 \\
Universidade Federal do Ceará (UFC) & 7 & 10,6 \\
Universidade Federal da Paraíba (UFPB) & 5 & 7,6 \\
Universidade Federal de Pernambuco (UFPE) & 4 & 6,1 \\
Universidade Federal do Rio Grande do Norte (UFRN) & 6,1 \\
Universidade Federal do Piauí (UFPI) & 4 & 4,5 \\
Universidade Tiradentes (UNIT) & 3 & 4,5 \\
Universidade Estadual de Santa Cruz (UESC) & 3 & 4,5 \\
Universidade Federal da Bahia (UFBA) & 3 & 4,5 \\
Universidade Estadual do Ceará (UECE) & 3 & 3,0 \\
Universidade Estadual da Paraíba (UEPB) & 2 & 3,0 \\
Universidade Federal de Sergipe (UFS) & 2 & 3,0 \\
Universidade Federal Rural de Pernambuco (UFRPE) & 2 & 3,0 \\
Outras & 2 & 21,2 \\
\hline
\end{tabular}

Fonte: Elaborada pelos autores.

* Calculado em relação ao total de trabalhos analisados (66)

Constata-se, portanto, que o foco dos trabalhos do EPENN sobre EaD, no período analisado, é a educação superior, indicando o grande potencial de crescimento da pesquisa sobre essa modalidade na educação básica, em outras expressões de ensino (educação de jovens e adultos, educação especial etc.) e na educação continuada.

\section{CONSIDERAÇÕES FINAIS}

Este artigo analisou a produção científica do Norte e Nordeste relacionada à educação a distância, publicada nos anais do EPENN de 2009-2014 na categoria de comunicações orais. Constata-se o número ainda reduzido de trabalhos sobre o tema nesse evento, ao se comparar com a expansão da EaD no Brasil. Isso evidencia a pouca participação de especialistas em EaD nesse tipo de evento, que congrega pesquisadores dos diversos campos da pesquisa em Educação. Embora a modalidade 
de educação a distância responda por 15,8\% do número de matrículas na graduação em 2012, no País (INSTITUTO NACIONAL DE ESTUDOS E PESQUISAS EDUCACIONAIS ANÍSIO TEIXEIRA, 2014), foram encontrados apenas 66 trabalhos (1,6\% do total) nas quatro edições do EPENN investigadas.

Há necessidade de maior atenção dos pesquisadores quanto à qualidade dos trabalhos científicos oferecidos. A análise evidenciou problemas quanto à clara definição de objetivos, abordagem de pesquisa, método e técnicas de coleta e análise dos dados utilizados. Isso tem influência na imagem da área de educação perante outros campos de conhecimento, assim como põe em xeque a confiabilidade das pesquisas que deram suporte aos trabalhos publicados e o rigor na análise das comissões encarregadas de avaliá-los.

Os assuntos mais tratados pelos trabalhos analisados foram sobre "análise de curso em ambiente virtual de aprendizagem" e "formação de profissionais", compreendendo $57,6 \%$ (38) do total. Ademais, eles se detiveram prioritariamente na educação superior, incluindo graduação, especialização e extensão. Os trabalhos analisados foram, em sua maioria (72,7\%), aceitos e publicados no GT 16 - Educação e Comunicação.

As IES públicas dominam a produção científica sobre EaD nos trabalhos selecionados, com destaque para UFAL, UNEB, UFC e UFPB, que respondem juntas por $53,0 \%$ (35) da produção. Isso aponta para o fato de que essa área de pesquisa ainda tem muito espaço para crescer nas IES das regiões Norte e Nordeste.

Com amparo nos resultados, indica-se para as comissões organizadoras dos futuros EPENs que sejam mais rigorosas na definição de critérios de avaliação dos trabalhos aceitos e na orientação aos membros das comissões avaliadoras, a fim de se garantir maior qualidade e confiabilidade nas publicações aprovadas. Precisa-se fazer avançar a pesquisa em Educação alicerçada em princípios científicos, independentemente da adoção de uma abordagem qualitativa, quantitativa ou mista .

Para finalizar, propõe-se que as regionais Norte e Nordeste do FORPREd envidem esforços para reunir e preservar a memória dos EPENNs, desde sua primeira edição. Sugere-se a criação de espaço na página da ANPEd, onde se incluam todas as publicações resultantes desses eventos, desde sua primeira edição. Desse modo, qualquer pesquisador ou pessoa interessada poderá ter acesso ao que foi produzido no EPENN e poderá conhecer parte da história da pesquisa em Educação realizada no Brasil.

\section{REFERÊNCIAS}

AGGARWAL, A. K.; LYNN, S. A. Using continuous improvement to enhance an online course. Decision Sciences Journal of Innovative Education, v. 10, n. 1, p. 25-48, 2012.

ALVES, J. R. M. A história da EAD no Brasil. In: LITTO, F. M.; FORMIGA, M. M. M. (Org.). Educação a distância: o estado da arte. São Paulo: Pearson Education do Brasil, 2009. v. 1.

ANDRADE, A. L. B.; SANTOS, A. M. Análise das interações no ambiente virtual de aprendizagem Moodle no âmbito da tutoria. In: ENCONTRO DE PESQUISAS EM EDUCAÇÃO EM ALAGOAS, 5., 2010, Alagoas. Anais ... Alagoas: UFAL, 2010.

ANPED. Grupos de trabalho. Rio de Janeiro, [201-]. Disponível em: <http://www.anped.org.br/ grupos-de-trabalho>. Acesso em: 28 maio 2016.

ARETIO, L. G. La educacion a distancia: de la teoria a la práctica. Barcelona: Ariel, 2002.

9 Sobre esse tema, Shavelson e Towne (2002) oferecem instigante discussão.

Cad. Pesq., São Luís, v. 26, n. 1, p. 107-124, jan./mar., 2019. 
BRASIL. Decreto n 5.622, 19 de dezembro de 2005. Regulamenta o art. 80 da Lei n o 9.394, de 20 de dezembro de 1996, que estabelece as diretrizes e bases da educação nacional. Diário Oficial da União, Brasília, DF, 20 dez. 2005.

Decreto $n^{0} 5.800$, de 8 de junho de 2006. Dispõe sobre o Sistema Universidade Aberta do Brasil - UAB. Diário Oficial da União, Brasília, DF, 9 jun. 2006.

. Lei $n^{\circ}$ 9.394, de 20 de dezembro de 1996. Estabelece as diretrizes e bases da educação nacional. Diário Oficial da União, Brasília, DF, 23 dez. 1996.

. Ministério da Educação. Parâmetros Curriculares Nacionais: Ensino Médio. Brasília: MEC, 2000. Disponível em: <http://portal.mec.gov.br/seb/arquivos/pdf/blegais.pdf>. Acesso em: 25 jan. 2015.

- Ministério da Educação. Secretaria de Educação a Distância. Referenciais de qualidade para a educação superior a distância. Brasília, DF, 2007. Disponível em: <http:// portal.mec.gov.br/seed/arquivos/pdf/referenciaisead.pdf>. Acesso em: 05 set. 2014.

. Resolução CNE/CES n 1, de 11 de março de 2016. Estabelece Diretrizes e Normas Nacionais para a Oferta de Programas e Cursos de Educação Superior na Modalidade a Distância. Diário Oficial da União, Brasília, DF, 14 mar. 2016.

BRINDLEY, J. E. Apoio ao aluno em educação online: essencial e evoluindo. In: ZAWACKIRITCHTER, O.; ANDERSON, T. Educação a distância online: construindo uma agenda de pesquisa. São Paulo: Artesanato Educacional, 2015. p. 295-318.

CAMBRUZZI, W. L. GVWISE: uma aplicação de learning analytics para a redução da evasão na educação a distância. 2014. 76 f. Dissertação (Mestrado em Computação Aplicada)Universidade do Vale do Rio dos Sinos, São Leopoldo, 2014.

CONOLE, G. O uso da tecnologia em educação a distância. In: ZAWACKI-RITCHTER, O.; ANDERSON, T. Educação a distância online: construindo uma agenda de pesquisa. São Paulo: Artesanato Educacional, 2015. p. 221-241.

CRESWELL, J. W; CLARK, V. L. P. Pesquisa de métodos mistos. 2. ed. Porto Alegre: Penso, 2013.

FERGUSON, R. Learning analytics for open and distance education. CEMCA EdTech Notes, p. 1-8, 2013. Disponível em: <http://cemca.org.in/ckfinder/userfiles/files/EdTech\%20 Notes_LA_Rebecca_15\%20May.pdf>. Acesso em: 3 jun. 2015.

FERREIRA, N. S. A. As pesquisas denominadas estado da arte. Revista Educação e Sociedade, n. 79, p. 257-272, 2002.

GAIO, R.; CARVALHO, R. B.; SIMÕES, R. Métodos e técnicas de pesquisa: a metodologia em questão. In: GAIO, R. (Org.). Metodologia de pesquisa e produção de conhecimento. Petrópolis-RJ: Vozes, 2008. p. 147-171.

GARRISON, D. R. Understanding Distance Educacion. A Framework for the future. Londres, Routledge, 1989.

GONÇALVES, M. T. L. Política de formação de professores em EaD: o desafio da universidade aberta. In: ENCONTRO DE PESQUISADORES, 21.; SEMANA UNIVERSITÁRIA DA UECE, 20., 2015, Fortaleza-CE. Anais... Fortaleza: UECE, 2015. p. 1-18. 
GROSSI, M. G.; KOBAYASHI, R. M. A construção de um ambiente virtual de aprendizagem para educação a distância: uma estratégia educativa em serviço. Revista da Escola de Enfermagem da USP, v. 47, n. 3, p. 756-760, 2013.

GUBA, E. G.; LINCOLN, Y. S. Competing paradigms in qualitative research. In: DENZIN, N. K.; LINCOLN, Y. S. (Ed.). Handbook of qualitative research. Thousand Oaks-California: SAGE, 1994. p. 105-117.

INSTITUTO NACIONAL DE ESTUDOS E PESQUISAS EDUCACIONAIS ANÍSIO TEIXEIRA. Censo da educação superior 2011: resumo técnico. Brasília: INEP, 2013. Censo da educação superior 2012: resumo técnico. Brasília: INEP, 2014.

KENSKI, V. M. Educação e tecnologias: o novo ritmo da informação. Campinas: Papirus, 2007.

KIPNIS, B. Educação superior a distância no Brasil: tendências e perspectivas. In: LITTO, F. M.; FORMIGA, M. M. M. (Org.). Educação a distância: o estado da arte. São Paulo: Pearson Education do Brasil, 2009. p. 209-214. v. 1.

LATCHEM, C. Garantia de qualidade na educação a distância online. In: ZAWACKIRITCHTER, O.; ANDERSON, T. Educação a distância online: construindo uma agenda de pesquisa. São Paulo: Artesanato Educacional, 2015. p. 319-353.

LITTO, F. M. O atual cenário Internacional da EAD. In: LITTO, F. M.; FORMIGA, M. M. M. (Org.). Educação a distância: o estado da arte. São Paulo: Pearson Education do Brasil, 2009. p. 14-20. v. 1.

LITTO, F. M.; FORMIGA, M. M. M. (Org.). Educação a distância: o estado da arte. São Paulo: Pearson Education do Brasil, 2009. v. 1.

MAIA, C.; MATTAR, J. ABC da EAD: a educação a distância hoje. São Paulo: Pearson Prentice Hall, 2007.

MARTINS, H. G. Educação corporativa: educação e treinamento nas empresas. In: LITTO, F. M.; FORMIGA, M. M. M. (Org.). Educação a distância: o estado da arte. São Paulo: Pearson Education do Brasil, 2009. p. 224-229. v. 1.

MATTAR, J. Interatividade e aprendizagem. In: LITTO, F. M.; FORMIGA, M. M. M. (Org.). Educação a distância: o estado da arte. São Paulo: Pearson Education do Brasil, 2009. p. 112-119. v. 1.

MOORE, M.; KEARSLEY, G. Educação a distância: uma visão integrada. São Paulo: Thomson Learning, 2007.

MORAN, J. M. A educação que desejamos: novos desafios e como chegar lá. Campinas: Papirus, 2007.

MOTA, R. A Universidade Aberta do Brasil. In: LITTO, F. M.; FORMIGA, M. M. M. (Org.). Educação a distância: o estado da arte. São Paulo: Pearson Education do Brasil, 2009. p. 297-303. v. 1.

NUNES, I. B. A história da EAD no Mundo. In: LITTO, F. M.; FORMIGA, M. M. M. (Org.). Educação a distância: o estado da arte. São Paulo: Pearson Education do Brasil, 2009. p. 2-8. v. 1. 
NUNES, J. B. C. Tecnologias digitais, política educacional e formação de professores. In: NUNES, J. B. C.; OLIVEIRA, L. X. (Org.). Formação de professores para as tecnologias digitais: software livre e educação a distância. Brasília: Liber Livro, 2012. p. 39-56. v. 1.

NUNES, J. B. C.; NOBRE, J. G.; SAMPAIO, D. S. Retrato da produção científica brasileira sobre analítica da aprendizagem: potencial para a educação a distância. In: ENCONTRO DE PESQUISA EDUCACIONAL DO NORTE E NORDESTE, 21., 2013, Recife. Anais... Recife: UFPE, 2013. p. 1-17.

PETERS, O. Prefácio. In: ZAWACKI-RITCHTER, O.; ANDERSON, T. Educação a distância online: construindo uma agenda de pesquisa. São Paulo: Artesanato Educacional, 2015. p. XIX-XXII.

PINTO, I. M. B. S. Evasão nos cursos de educação a distância da UAB/UFAL. In: ENCONTRO DE PESQUISA EDUCACIONAL DO NORTE E NORDESTE, 19., 2009, João Pessoa. Anais... João Pessoa: UFPB, 2009. p. 1-12.

RAPOSO, M. R. Competência digital e a EAD. In: LITTO, F. M.; FORMIGA, M. M. M. (Org.). Educação a distância: o estado da arte. São Paulo: Pearson Education do Brasil, 2012. p. 7174. v. 2.

ROMANOWSKI, J. P.; ENS, R. T. As pesquisas denominadas do tipo "estado da arte" em educação. Revista Diálogo Educacional, Curitiba, v. 6, n. 19, p. 37-50, 2006.

RUSSELL, T. L. The no significant difference phenomenon. Raleigh-North Carolina: State University, 1999.

SABBATINI, M. O tecnicismo revisitado: contribuições dos fundamentos da educação para o debate da Educação a Distância (EAD). In: ENCONTRO DE PESQUISA EDUCACIONAL DO NORTE E NORDESTE, 22., 2014, Natal. Anais... Natal: UFRN, 2014. p. 1-20.

SÁ-SILVA, J. R.; ALMEIDA, C. D. de; GUINDANI, J. F. Pesquisa documental: pistas teóricas e metodológicas. Revista Brasileira de História \& Ciências Sociais, n. 1, 2009.

SCLATER, N.; PEASGOOD, A.; MULLAN. J. Learning analytics in higher education. Londres: Jisc, 2016. Relatório. Disponível em: <https://www.jisc.ac.uk/sites/default/files/learninganalytics-in-he-v2_0.pdf>. Acesso em: 1 jun. 2017.

SHAVELSON, R. J.; TOWNE, L. (Ed.). Scientific research in education. Washington: National Academy Press, 2002.

SIEMENS, G. Connectivism: a learning theory for the digital age. International Journal of Instructional Technology and Distance Learning, v. 2, n. 1, p. 3-10, 2005. Disponível em: <http://www.itdl.org/journal/jan_05/article01.htm>. Acesso em: 3 jun. 2017.

Connectivism: learning theory or pastime for the self-amused? Elearnspace, nov. 2006. Disponível em: <http://www.elearnspace.org/Articles/connectivism_self-amused.htm>. Acesso em: 3 jun. 2017.

TEDESCO, P.; MARTINS, I.; SANTOS, M. Tecnologias aplicadas à educação a distância. Recife: UFRPE, 2010. v. 1.

TRACTENBERG, L.; TRACTENBERG, R.; AZEVEDO JUNIOR, W. C. A docência on-line independente. In: LITTO, F. M.; FORMIGA, M. M. M. (Org.). Educação a distância: o estado da arte. São Paulo: Pearson Education do Brasil, 2012, p. 258-264. v. 2.Submetido em agosto de 2018. Aceito em fevereiro de 2019. 